\title{
Biodiesel Production by Pichia occidentalis MH879824.1
}

\author{
Laila Ramadan, Yasser Fathy Abdelaliem* and Salem Abdelfattah Mahfoz
}

Department of Agricultural Microbiology, Faculty of Agricultural, Fayoum University, Egypt

*Corresponding author

\begin{tabular}{|c|c|}
\hline & A B S T R A C T \\
\hline $\begin{array}{l}\text { Ke y w o r d s } \\
\text { Honey Oleaginous } \\
\text { yeasts, Biodiesel, } \\
\text { lipid extraction, } \\
\text { Fatty acids analysis, } \\
\text { 26S rDNA gene, } \\
\text { Nitrogen-limited } \\
\text { medium }\end{array}$ & \multirow{3}{*}{$\begin{array}{l}\text { A lipid producing isolate (LPI 65) was identified by a molecular genetics technique as } \\
\text { Pichia occidentalis MH879824.1 was investigated for its ability to produce biodiesel. The } \\
\text { isolate was screened for its ability to accumulate lipids within the cells by culturing on } \\
\text { nitrogen-limited medium (NLM) and using Sudan black B staining technique. Estimation } \\
\text { of lipid content \% was performed. The effect of different glucose concentrations in NLM } \\
\text { on dry biomass and lipid weight were conducted and results showed that the best } \\
\text { concentration of glucose was } 70 \mathrm{~g} / \mathrm{L} \text {. The possibility of using different wastes such as } \\
\text { sugar cane molasses, waste food oil and shortening, whey permeate, and waste motor oil as } \\
\text { carbon sources for lipid production were determined, and the results showed that the best } \\
\text { waste for lipid production was waste motor oil. Optimization of fermentation conditions } \\
\text { such as effect of NLM composition, NLM pH, incubation temperature, and incubation } \\
\text { period were also investigated and results of these tests showed that the best lipid } \\
\text { accumulation when NLM5, at pH 5.5 and incubated at } 280 \mathrm{o} \text { for } 120 \text { h. Fatty acids profile } \\
\text { analysis achieved that the lipids extracted from the isolate mainly contained the principal } \\
\text { fatty acids (triacylglycerol's, TAGs) which are similar to that of vegetable oils mainly } \\
\text { oleic, linoleic and palmitic acid. }\end{array}$} \\
\hline Article Info & \\
\hline $\begin{array}{l}\text { Accepted: } \\
20 \text { March } 2019 \\
\text { Available Onl } \\
10 \text { April } 2019\end{array}$ & \\
\hline
\end{tabular}

\section{Introduction}

In the last few decades, oil prices have been experiencing an increasing trend. The main sources used in the energy and transport sector are still petroleum based. However, the gap is closing as a result in reducing production costs of bio-based materials (Martínez et al., 2015). In the same way, bioethanol and biodiesel are still the main biofuels used in transport applications, with biogas also presenting a few large-scale applications in some localized European areas. The extensive use of liquid biofuels was initially controversial due to the impacts on food prices. Advanced biofuels, although it is a term that is not yet well defined, are rapidly becoming a reality. These fuels may be defined based on the conversion technologies used, which are still in the research and development pilot or demonstration phases, and are commonly referred to as second- or third-generation biofuels (Balan et al., 2013). In 1993, Ratledge stated that lipids accumulating microorganisms called oleaginous microorganisms are defined as microbes with the capacity to accumulate a lipid content of 
greater than $20 \%$. Lipids produced from these types of microorganisms are known as single cell oils (SCO) to clearly identify their origin from microbial sources. The oil produced has the same triacylglycerol (TAGs) structure as plant oils. While Zhang et al., (2011) found that as a major component of cell membranes, fatty acids are synthesized in high flux and converted into phospholipids in all organisms. The long hydrocarbon chain is energy-rich, which makes it an ideal precursor for biofuels.

The advantages of utilizing biodiesel replacing conventional fuel are that biodiesel in engines are non-toxic, biodegradable, renewable and less pollutant in emissions. Engine life can be prolonged by reducing the frequency of engine part replacement and by increasing the lubricity. Due to the high cost of feedstock used for biodiesel synthesis, it is not yet globally commercialized. The oleaginous yeasts are the best source as biodiesel producer and can be used for future research programs Karthika and Karthika, 2018).

More than $95 \%$ of biodiesel production feed stocks come from edible oils, which exert a lot of pressure on the cost of raw materials. Moreover, it is a cause of deforestation in some countries due to the increase in agricultural land required (Leung et al., 2010, and Olkiewicz et al., 2012). The use of waste cooking oil as a feedstock may represent a reasonable alternative that also solves the problem of waste oil disposal (Lin et al., 2011 and Fierro et al., 2014).

The use of low-cost carbon sources for the production of SCO has been extensively studied as a mean of reducing costs, and thus becoming competitive with traditional energy crops for oil production (Helwani et al., 2009, Li and Wang 1997, and Gouda et al., 2008). Alvarez and Rodriguez (1992) stated that molasses has not been traditionally studied as a suitable substrate due to its high content of organic nitrogen.

The study of Katre et al., 2012 is one of the few reports of the conversion of waste cooking oil and motor oil into valuable lipids. Nigrocincta (Denise et al., 2002). Most microorganisms do not grow in honey because of its low water activity of 0.6 (Molan, 1992). Hydrogen peroxide, methylglyoxal, bee defensin, $\mathrm{pH}$, osmotic effect as well as leptosin were known to be responsible for the antimicrobial effects of honey (Mandal, 2011; Kato et al., 2012).

\section{Materials and Methods}

\section{Yeast isolation}

Pickle Carrots sample was serially diluted and added to plates, then YEPD medium (Glucose - 2.0\%, Yeast Extract - 1.0\%, peptone - 2.0\% $\mathrm{pH}-6.0)$ was poured. Plates were incubated at $28^{\circ} \mathrm{C}$ for $48 \mathrm{hrs}$. Selected colonies were further streaked on YEPD plates to obtain pure culture (Pan et al., 2009).

\section{Cultivation medium}

Nitrogen-limited medium Marjan et al., (2013) with some modifications) which containing g/L Glucose 70.0, $\left(\mathrm{NH}_{4}\right)_{2} \mathrm{SO}_{4}$ 2.0, $\mathrm{KH}_{2} \mathrm{PO}_{4} 7.0, \mathrm{MgSO}_{4} \cdot 7 \mathrm{H}_{2} \mathrm{O} 1.5, \mathrm{NaH}_{2} \mathrm{PO}_{4} 2.0$, Yeasts extract 0.75 , pH 5.5 was used.

\section{Qualitative assay of lipid production from} yeast

The purified yeast culture cultivated on NLM Marjan et al., (2013) and after 5 days of incubation period at $28-30{ }^{\circ} \mathrm{C}$, the yeast culture was further screened for its cellular lipid by qualitative analysis with Sudan black B staining technique according to (Anuradha et al., 2014) . 


\section{Cultivation of yeast for lipid production}

\section{Standard inoculum}

Standard inoculum of the isolate prepared by inoculation of conical flask ( $250 \mathrm{ml}$ volume) containing $50 \mathrm{ml}$ of inoculum's medium (Pan et al., 2009) with a loop of the tested yeast. The inoculated flask was incubated on rotary shaker $(160 \mathrm{rpm})$ for 48 hours at $28^{\circ} \mathrm{C}$. Under aseptic conditions, five $\mathrm{ml}$ of the content of the flask was used as an inoculum for $50 \mathrm{ml}$ of productive medium.

\section{Lipid production}

Five $\mathrm{ml}$ of propagated culture of yeast isolate was transferred into flasks containing $50 \mathrm{ml}$ of production medium, then incubated at 28 ${ }^{\circ} \mathrm{C}$ in shaking incubator (160 rpm) for 5 days (Pan et al., 2009). Total yeast lipids were extracted according to the procedures described by Bligh and Dyer (1959) with modifications described by (Pan et al., 2009), then lipid content was determined. A $50 \mathrm{ml}$ sample was centrifuged at $5000 \mathrm{rpm}$ for 10 min, after that the yeast cells were washed twice with $50 \mathrm{ml}$ of distilled water, and then $10 \mathrm{ml}$ of $4 \mathrm{M} \mathrm{HCl}$ were added into, and incubated at $60{ }^{\circ} \mathrm{C}$ for 1 to $2 \mathrm{~h}$. Then the acidhydrolyzed mass was stirred with $20 \mathrm{ml}$ of chloroform/methanol mixture (1:1) at room temperature for 2 to $3 \mathrm{~h}$, followed by centrifugation at $2000 \mathrm{~g}$ for $5 \mathrm{~min}$ at room temperature to separate the aqueous upper phase and organic lower phase. After that the lower phase containing lipids was recovered with a Pasteur pipette, and evaporated at room temperature. The dry lipids were weighed.

\section{Effect of carbon sources on lipid production}

The influence of carbon sources (Glucose, sugar cane molasses, whey permeate, waste food oil, waste food shortening, and waste motor oil) on biomass weight and lipid production were investigated.

\section{Effect of glucose concentration}

The propagation was carried out as mentioned before and the cultures were inoculated in basal NLM with different glucose concentrations being 40,70 , and $100 \mathrm{~g} /$ liter.

\section{Effect of sugar cane molasses concentration}

Sugar cane molasses was obtained from Sugar \& Integrated Industries Company in $\mathrm{Al}-$ Hawamdeya, Egypt, and kept in refrigerator at $4^{\circ} \mathrm{C}$ until used. Molasses was diluted with water in an equal volume using the method of Johnson et al., (1995) with some modifications.

The concentration of sugar cane molasses was at $83.2,145.8$, and 208.2 which equalize 40 , 70 , and $100 \mathrm{~g} / \mathrm{L}$ glucose respectively, then completed to one liter and the components of NLM except glucose were added.

\section{Effect of whey permeate}

Whey permeate sample was obtained from the model dairy unit, Faculty of Agriculture, Fayoum University, and stored at $4{ }^{\circ} \mathrm{C}$ for the preparation of the fermentation medium. Whey permeate was sterilized at $121{ }^{\circ} \mathrm{C}$ for $15 \mathrm{~min}$ for coagulation of protein residues and then filtered through filter paper.

The supernatant was collected and used with the components of NLM g/L glucose $20 \mathrm{~g}$ $\left(\mathrm{NH}_{4}\right)_{2} \mathrm{SO}_{4} 2 \mathrm{~g}-\mathrm{kH}_{2} \mathrm{PO}_{4} 7 \mathrm{~g}-\mathrm{NaH}_{2} \mathrm{PO}_{4} 2 \mathrm{~g}-$ $\mathrm{MgSO}_{4} .7 \mathrm{H}_{2} \mathrm{O} 1.5 \mathrm{~g}-$ Yeast extract $0.75 \mathrm{~g}$ and added to a liter of permeate $(20 \mathrm{~g}$ glucose/ $\mathrm{L}$ which equal $70 \mathrm{~g}$ sugar/L). The components of NLM without any carbon source were added to a liter of permeate (control) as described by Ykema et al., (1988). 
Effect of waste motor oil, waste food oil, and waste food shortening as carbon sources

Waste food oil, used in the present study was obtained from local market of Fayoum Egypt, from shop selling fried vegetables (potatoes, green pepper, eggplant, and falafel), and Waste food shortening obtained from local market of Fayoum - Egypt, from shop selling different types of fast food such as, chicken, meat products, waste motor oil was obtained from Fayoum - Egypt also. Using the method of Heba El Bialy et al., (2011) with some modifications, each type of oil $(5,10$, and $15 \mathrm{~g})$ were added to tween 80 : water (25: 75) and autoclaved separately. Autoclaved oil was aseptically mixed with basal medium at a final content 5, 10, and 15 $\mathrm{g} / \mathrm{L}$. Glucose concentration used in this experiment was $10 \mathrm{~g} / \mathrm{L}$ for waste food oil, and shortening, and waste motor oil supplemented medium as growth starter for yeast isolates.

\section{Optimization of fermentation conditions for lipid production}

Effect of NLM composition, NLM pH, incubation temperature, and incubation period were also investigated. Different five nitrogen limited media, NLM 1 Gao-Qiang et al., (2010), NLM 2 Pan, et al., (2009), NLM 3 Gohel et al., (2013), NLM 4 Pirozzi et al., (2014), and NLM 5 Marjan et al., (2013) with some modifications were used, $\mathrm{pH}$ was 4.5 , $5.0,5.5$, and 6.0, incubation temperature was 25,28 , and $35^{\circ} \mathrm{C}$, and incubation period was 96,120 , and $144 \mathrm{~h}$.

\section{Fatty acids analysis (GC- MS fraction) of extracted lipids}

Fatty acids analysis was confirmed at Oil and Fat Research Institute, Agricultural Research Center (ARC), Giza, Egypt.

\section{Preparation of fatty acids methyl esters}

Fatty acids methyl esters prepared from total lipids by using rapid method according to the method of ISO 12966-2 (2011). Where, fatty acids methyl esters were formed by transesterification with methanolic potassium hydroxide as an intermediate stage before saponification take place. Approximately $0.1 \mathrm{~g}$ of the lipid sample was placed in $5 \mathrm{ml}$ screwtop test tube and $2 \mathrm{ml}$ of isooctane were added to the tube then the tube was shaken. Methanolic potassium hydroxide solution (0.1 $\mathrm{ml}, 2 \mathrm{~N}$ ) was put on the cap fitted with a Polytetrafluoroethylene (PTFE)- joint, tighten the cap, and shaken vigorously for 30 seconds. The tube was left to stratify until the upper solution became clear and the upper layer containing the methyl ester was decanted. The isooctane solution is suitable for injection into the gas chromatography.

Gas liquid chromatography (GLC) of methyl esters of fatty acids

Fatty acids methyl esters were injected in to (HP 6890 series GC) apparatus provided with a DB- 23 column $(60 \mathrm{~m} \times 25 \mu \mathrm{m})$. Gas carrier was $\mathrm{N}_{2}$ with flow rate $2.2 \mathrm{ml} / \mathrm{min}$, splitting ratio of 1:50. The injector temperature was $250^{\circ} \mathrm{C}$ and that of flame ionization detector (FID) was $300^{\circ} \mathrm{C}$. The temperature setting was as follows: $150{ }^{\circ} \mathrm{C}$ to $210{ }^{\circ} \mathrm{C}$ at $5^{\circ} \mathrm{C} / \mathrm{min}$, and then held at $210{ }^{\circ} \mathrm{C}$ for $25 \mathrm{~min}$. Peaks were identified by comparing the retention times obtained with standard methyl esters.

\section{Yeast identification}

Yeast isolate was identified according to (White et al., 1990). Sequences were further analyzed using Basic Local Alignment Search Tool (BLAST) from the National Center of Biotechnology Information (NCBI) website. Phylogenetic analysis of sequences was done with the help of MegAlign (DNA Star) software version 5.05. 


\section{Results and Discussion}

Effect of carbon sources on lipid production

The effect of glucose concentrations in NLM on lipid production

Data in Figure 1 indicate the effect of different glucose concentrations as a carbon source on the production of dry biomass, and lipid weight. The addition of $70 \mathrm{~g}$ glucose gave $26.0 \mathrm{~g}$, and $11.6 \mathrm{~g}$ for the both parameters, respectively. These results are higher than those obtained by Ratanaporn, and Ratanaporn (2011) which was $8.8 \mathrm{~g} / \mathrm{L}$ dry biomass and $4.1 \mathrm{~g} / \mathrm{L}$ lipid production at a concentration of glucose $80 \mathrm{~g} / \mathrm{L}$, and in agreement with the results obtained by Gohel et al., (2013) who showed that the best concentration of glucose for lipid production was $70 \mathrm{~g} / \mathrm{L}$.

\section{Effect of sugar cane molasses as a carbon} source on lipid production

Data in Figure 2 indicate the effect of sugar cane molasses as a carbon source on the production of dry biomass, and lipid weight. Isolate LPI 65 gave $11.8 \mathrm{~g}$ for lipid weight when $83.2 \mathrm{~g}$ (40 g sugar) were used, while the highest dry biomass $32.7 \mathrm{~g} / \mathrm{L}$ was obtained when $208.2 \mathrm{~g}$ molasses (100 g sugar) were added to the fermentation medium. These results are better than those obtained by Noura El-Naggar et al., (2011) who used 4.2 $\mathrm{g}$ sugar cane molasses with Candida albicans, where cell weight and lipid weight only reached $6.5 \mathrm{~g} / \mathrm{L}$ and $1.1 \mathrm{~g} / \mathrm{L}$, respectively.

\section{Effect of whey permeate as a carbon source on lipid production}

Results in Figure 3 revealed that the addition of $20 \mathrm{~g}$ glucose gave the highest dry biomass and lipid production with the tested isolate.
The LPI65 gave $37.8 \mathrm{~g}$ dry biomass superior to the control which only gave 8.47. Recording lipid weight, it is clear that the addition of $20 \mathrm{~g}$ glucose gave more than three times the control; 10.4 and $3.4 \mathrm{~g}$, respectively.

\section{Effect of using different concentrations of waste motor oil as a carbon source on lipid production}

Data in Figure 4 illustrate the effect of using different concentrations of waste motor oil as a carbon source on the production of dry biomass, and lipid weight. The addition of 15 $\mathrm{g} / \mathrm{L}$ waste motor oil gave $18.09 \mathrm{~g}, 14.6 \mathrm{~g}$ for the both parameters, respectively, followed by 10 and $5 \mathrm{~g} / \mathrm{L}$.

Effect of using different concentrations of waste food oil as a carbon source on lipid production

Batch cultures were investigated to determine the possibility of using waste food oil as a carbon source for lipid production. Data in Figure 5 show the effect of using different concentrations of waste food oil as a carbon source on the production of dry biomass, and lipid weight. The highest dry biomass and lipid weight 36.6 and 5.2, respectively, were obtained when $15 \mathrm{~g} / \mathrm{L}$ waste food oil were added. The results in this study are higher than those obtained by Heba El Bialy et al., (2011) who reported that the maximum lipid content was $12.9 \%$, and dry biomass was $9.12 \mathrm{~g} / \mathrm{L}$ whereas in the present study the maximum lipid content and the maximum dry biomass was $44.0 \%$ and $36.6 \mathrm{~g} / \mathrm{L}$ respectively.

\section{Effect of using of waste food shortening as} a carbon source on lipid production

Batch cultures were investigated to determine the possibility of using waste food shortening as a carbon source for lipid production. In Figure 6 data show that the highest dry 
biomass and lipid weight $40.1 \mathrm{~g}$ and 5.2, respectively, were obtained when $15 \mathrm{~g} / \mathrm{L}$ waste food shortening were added. It s clear that the higher concentration of waste food shortening, the highest biomass and lipid.

\section{Optimization of fermentation conditions for lipid production}

\section{The effect of NLM pH on lipid production}

The growth and lipid production of yeast were affected by the medium $\mathrm{pH}$ as shown in Figure 7. Isolate LPI 65 gave the highest dry biomass $35.2 \mathrm{~g}$ when $\mathrm{pH}$ was 6.0 , but the highest lipid $12.0 \mathrm{~g}$ was recorded, when the $\mathrm{pH}$ was 5.5. These results are in agreement with those obtained by El - Fadaly et al., (2009) who showed that the best initial $\mathrm{pH}$ was 5.5 for the production of cell biomass and lipids.
The effect of incubation temperature on lipid production

Data in Figure 8 indicate the effect of different incubation temperatures on the production of dry biomass, and lipid weight. The highest dry biomass and lipid weight 22.8 $\mathrm{g}$ and $9.9 \mathrm{~g}$ were obtained at $28^{\circ} \mathrm{C}$. These results disagree with the results obtained by Noura El-Naggar et al., (2011) who showed that the best incubation temperature was $25^{\circ} \mathrm{C}$ for the production of cell biomass and lipids. When the temperature increased to $28^{\circ} \mathrm{C}$ the growth rate decreased, while $25{ }^{\circ} \mathrm{C}$ gave the highest dry biomass $(8.3 \mathrm{~g} / \mathrm{L})$, and the highest lipid weight $(1.6 \mathrm{~g} / \mathrm{L})$. The temperature $25^{\circ} \mathrm{C}$, gave the highest dry biomass $(12.8 \mathrm{~g} / \mathrm{L})$, and the highest lipid weight (7.2 g/L) Marjan et al., (2013).

Table.1 Fatty acids analysis (GC- fraction) of extracted lipids

\begin{tabular}{|c|c|c|}
\hline \multicolumn{2}{|c|}{ Fatty acids } & Fatty acids \\
\hline Name & Symbol & LPI 65 \\
\hline Myristic acid & C14:0 & 0.68 \\
\hline Myristoleic acid & C14:1 & 0.18 \\
\hline Pentadecanoic acid & C15:0 & 0.24 \\
\hline Pentadecenoic acid & C15:1 & 1.00 \\
\hline Palmitic acid & C16:0 & 15.10 \\
\hline Palmitoleic acid & C16:1 & 5.57 \\
\hline Heptadecanoic acid & C17:0 & 1.08 \\
\hline Heptadecenoic acid & $\mathrm{C} 17: 1$ & 1.68 \\
\hline Stearic acid & C18:0 & 4.79 \\
\hline Oleic acid & C18:1 & 34.41 \\
\hline Linoleic acid & C18:2 & 19.96 \\
\hline Gamma-linolenic acid & C18:3n6 & 0.76 \\
\hline$\alpha$-Linolenic acid & $\mathrm{C} 18: 3 \mathrm{n} 3$ & 11.11 \\
\hline Stearidonic acid & C18:4 & 0.84 \\
\hline Arachidic acid & C20:0 & 1.10 \\
\hline Gondoic acid & C20:1 & 0.28 \\
\hline Eicosadienoic acid & C20:2 & 0.16 \\
\hline Arachidonic acid & C20:4 & 0.40 \\
\hline $\begin{array}{l}\text { Eicosatrienoic acid } \\
\text { methyl ester }\end{array}$ & C20:3n3 & 0.35 \\
\hline Behenic acid & $\mathrm{C} 22: 0$ & 0.06 \\
\hline $\begin{array}{l}\text { Eicosatetraenoic } \\
\text { acid }\end{array}$ & $\mathrm{C} 22: 4$ & 0.20 \\
\hline
\end{tabular}


Fig.1 The effect of glucose concentrations in NLM on lipid production

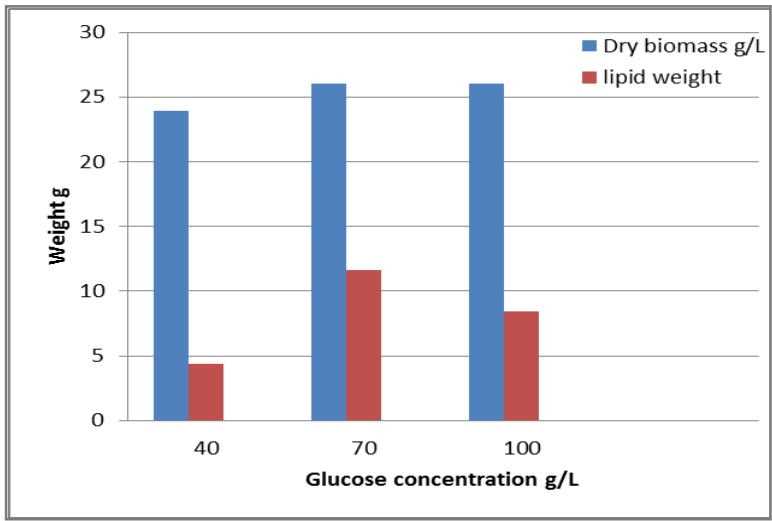

Fig.2 Effect of sugar cane molasses as a carbon source on lipid production

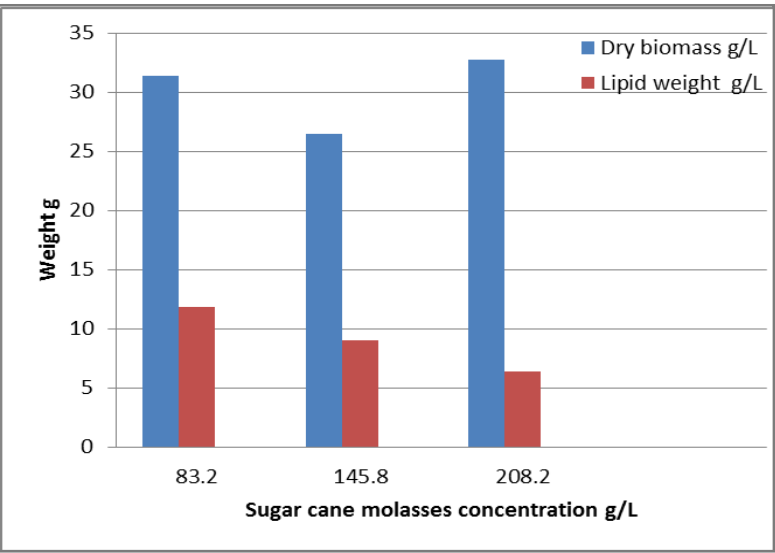

Fig.3 Effect of whey permeate as a carbon source on lipid production

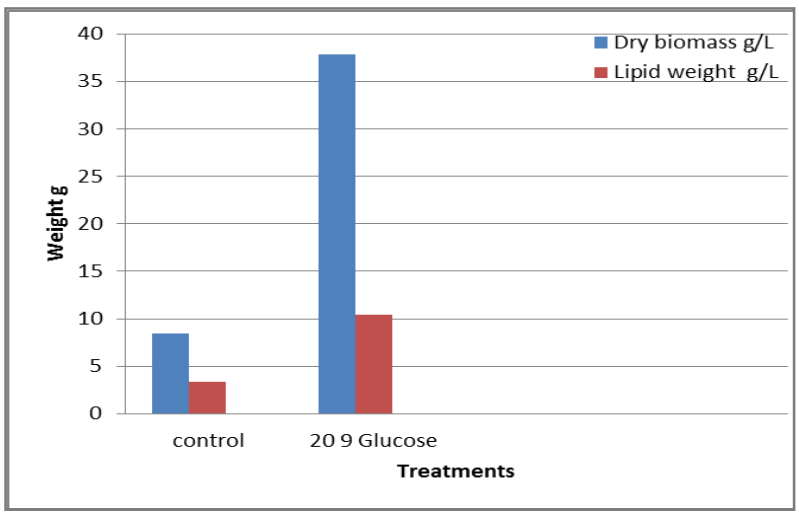


Fig.4 Effect of using waste motor oil as a carbon source on lipid production

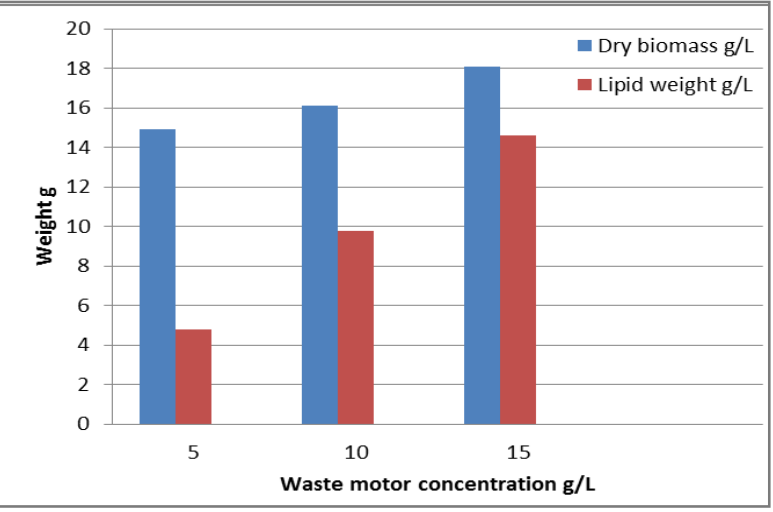

Fig.5 Effect of using different concentrations of waste food oil as a carbon source on lipid production

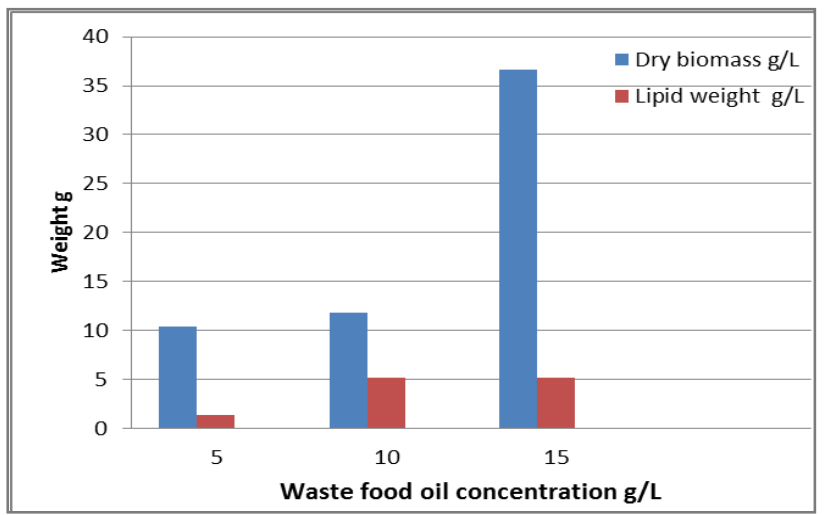

Fig.6 Effect of using waste food shortening as a carbon source on lipid production

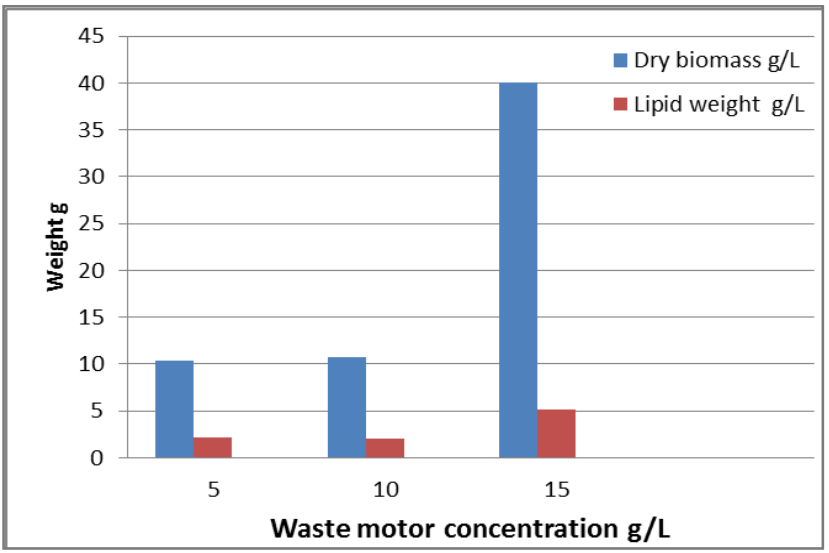


Fig.7 The effect of NLM pH on lipid production

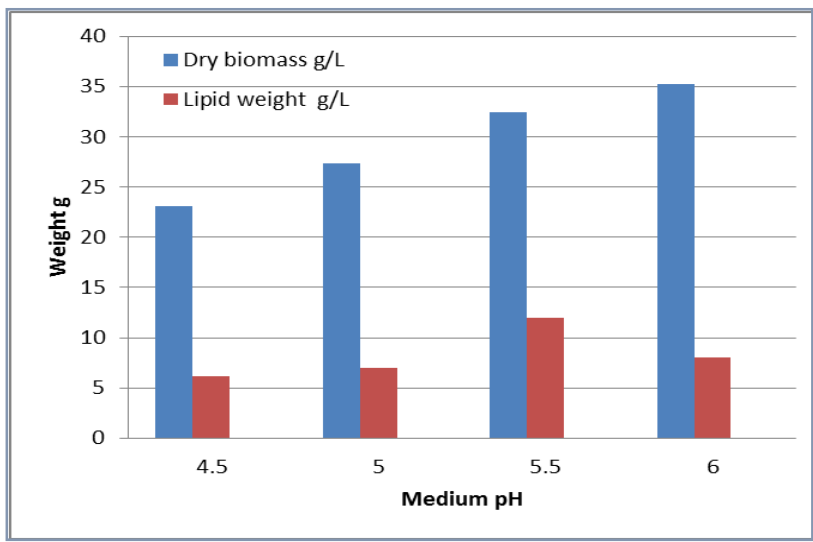

Fig.8 The effect of incubation temperature on lipid production

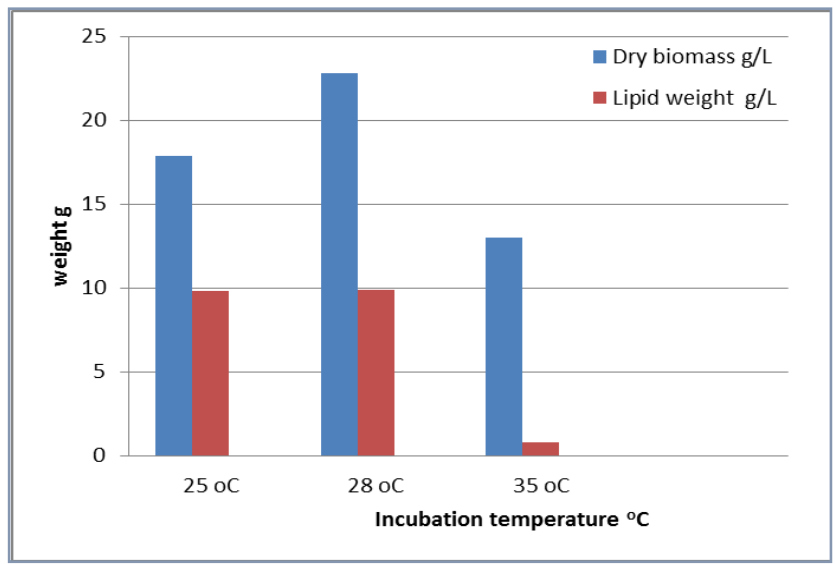

Fig.9 The effect of incubation period on lipid production

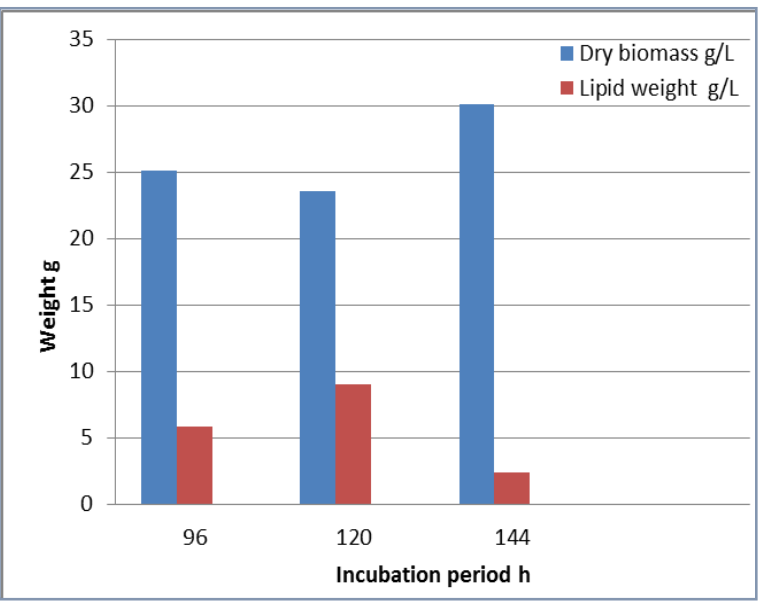


Fig.10 The effect of NLM composition on lipid production

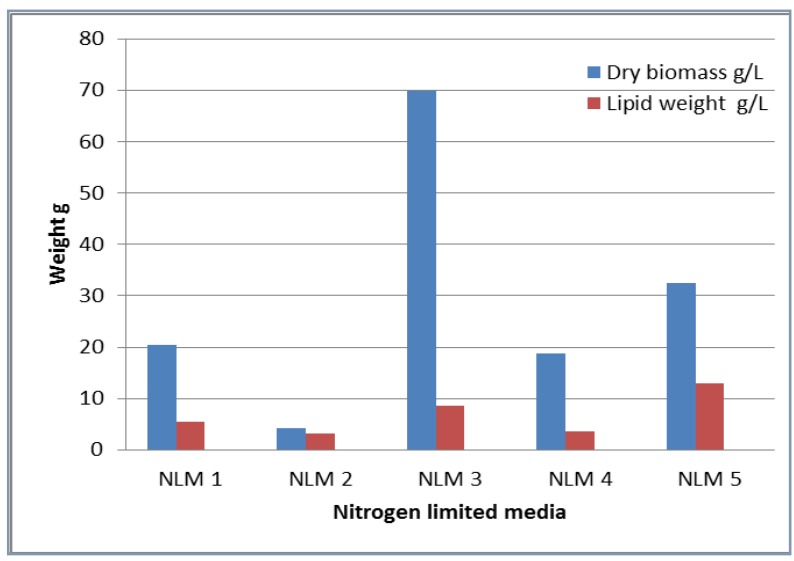

Fig.11 Chromatogram of fatty acids methyl esters of LPI 65

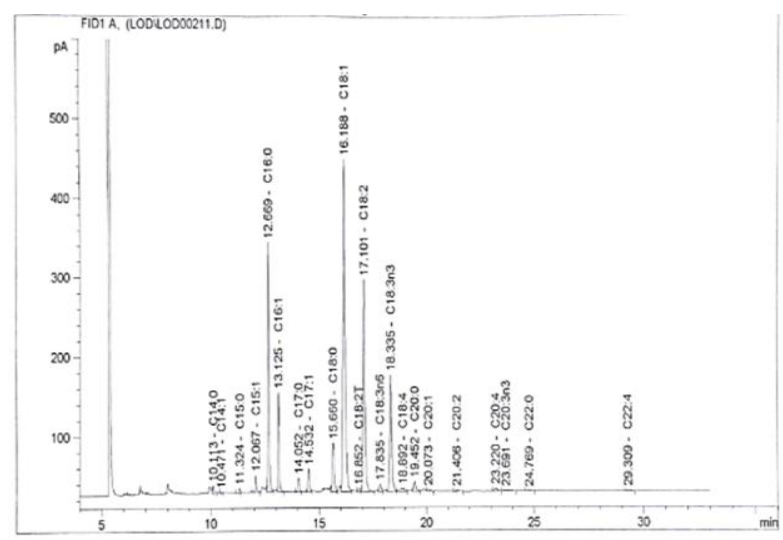

Fig.12 Contiguous of yeast LPI 65

GGCTAGGGATACTCTTCACACGTGCGTGAGCGCAAGCAAAACACGAAAAAACTGT AGTACGAGAGTCAAAACAAACCAAAAAACAAAACTTTCAACAACGGATCTCTTGG TTCTCGCATCGATGAAGAGCGCAGCGAAATGCGATACCTAGTGTGAATTGCAGCC ATCGTGAATCATCGAGTTCTT'GAACGCACATTGCGCCCTCTGGTATTCCGGAGGG CATGCCTGTTTGAGCGTCGTTTCCTTCTTGCTTGCGAGCAGAAATGGGGGGGCC TGGCATTGGGGCCGCTCTGAAAAGAAACGTTGCGGGCGAAGCGAACTATGAGTAG GACGCTTGGCCGCCGAACTTAATACATAAGCTCGACCTCAAATCAGGTAGGAATA CCCGCTGAACTTAAGCATATCAAAAGGCCGGAGGAA 
Fig.13 Phylogenetic tree of ITS sequences of rDNA from yeast samples isolated in the present study LPI 65, aligned with related sequences accessed from the Gen Bank

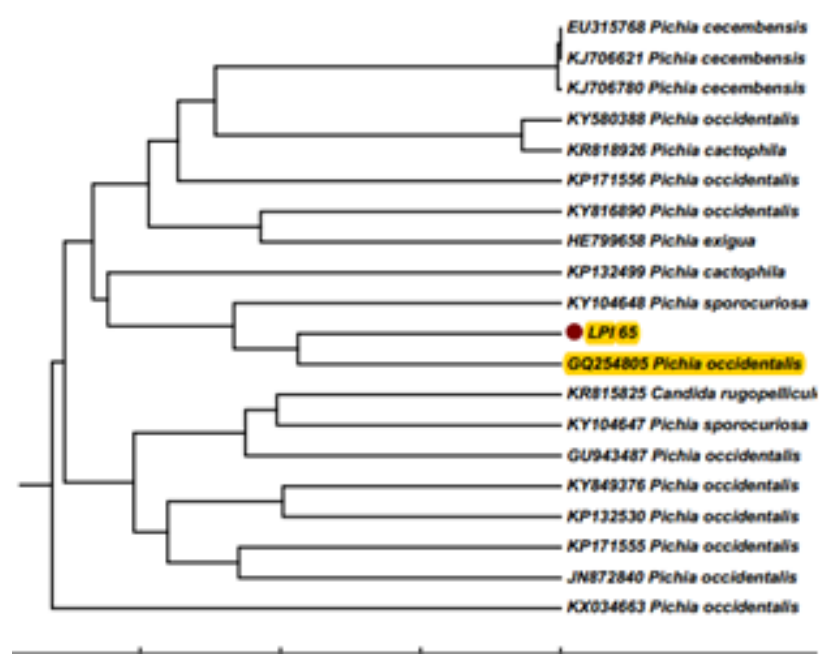

The effect of incubation period on lipid production

The growth and lipid production of yeasts were affected by fermentation period as shown in Figure 9. Data in the figure show the effect of different incubation periods on the production of dry biomass, and lipid weight. The highest dry biomass $30.1 \mathrm{~g}$ was obtained after $144 \mathrm{~h}$, but the highest lipid weight $9.0 \mathrm{~g}$ after $120 \mathrm{~h}$. These results disagree with those obtained by Noura ElNaggar et al., (2011), who showed that the best fermentation period was after $72 \mathrm{~h}$, where lipid content reached $20.0 \%$, where after $24 \mathrm{~h}$ lipid content was only $16.9 \%$. And after $72 \mathrm{~h}$ Marjan et al., (2013) reported that lipid content reached $57.5 \%$, where in the present study the highest lipid content reached $38.1 \%$ after $120 \mathrm{~h}$.

\section{The effect of NLM composition on lipid production}

Data in Figure 10 indicate the effect of NLM composition on the production of dry biomass, and lipid weight. The highest dry biomass $69.9 \mathrm{~g}$ was obtained on NLM 3, and the highest lipid weight $12.9 \mathrm{~g}$ was obtained on NLM 5. These results are higher than those obtained by Abdou, (2015) where NLM 1 gave $4.0 \mathrm{~g} / \mathrm{L}$ cell dry biomass, and lipid weight $0.82 \mathrm{~g} / \mathrm{L}$, less than the results obtained by Pan et al., (2009) NLM 2 gave $22.3 \mathrm{~g} / \mathrm{L}$ cell dry biomass, and lipid weight $5.6 \mathrm{~g} / \mathrm{L}$, and in agreement with those reported by Marjan et al., (2013) who also added that the production of lipids in the medium with glucose as a sole carbon source was more efficient than xylose in NLM 5, where glucose gave the highest cell dry biomass was $17.4 \mathrm{~g} / \mathrm{L}$, and the highest lipid weight $7.1 \mathrm{~g} / \mathrm{L}$, when the medium composition was modified with increasing glucose concentration to 70 $\mathrm{g} / \mathrm{L}$.

Fatty acids analysis (GC - MS fraction) of extracted lipids

The highest dominant fatty acid among the fatty acids profile of isolates LPI 65 was the oleic acid (C18:1) with content $59.48 \%$, followed by linoleic acid (C18:2) with content $19.96 \%$, palmitic acid (C16:0) with content $15.10 \%$, as shown in table 1 and Figure 11. These results are in agreement with those obtained by Dalia Abdel Mawla (2015), who showed that the highest dominant fatty acids 
were the oleic acid with content ranging from 27.85 to $55.69 \%$, followed by palmitic acid with content ranging from 16.08 to $31.52 \%$, which nearly the same percentage obtained in the present study.

\section{Yeast identification}

The 26SrDNA gene sequences of LPI 65 were compared with sequences in the Gene-Bank database. A phylogenetic tree based on 26SrDNA sequences Figure 12, revealed the affiliation of isolate LPI 65 to the genus Pichia, comprising $99 \%$ to $100 \%$ similarity with related strains of Pichia occidentalis MH879824 Figure 13.

\section{References}

Abdou, A. A. (2015). Yeasts as a promising tool for microbial oil production. M.Sc. Thesis, Fac. Agric., Cairo Univ.

Alvarez, R. M. and Rodriguez, B. (1992). Lipid accumulation in Rhodotorula glutinis on sugar cane molasses in single-stage continuous culture. World J. Microbiol. \& Biotechnol., 8: 214 215.

Anuradha, J., Abhay, H. and Sapre, V. R. (2014). Modified Sudan Black B staining method for rapid screening of oleaginous marine yeasts. Appl. Sci., 3 (9): 41 - 46.

Balan, V., Chiaramonti, D. and Kumar, S. (2013). Review of US and EU initiatives toward development, demonstration, and commercialization of lignocellulosic biofuels. Biofuels Bioprod. Bioref., 7: 732 - 759.

Dalia, M. M. Abd el Mawla (2015). Studies on Production of Biodiesel From Yeast. M.Sc. Thesis, Fac. Agric., Ain shams Univ.

El-Fadaly, H., Noura, A. El-Naggar and Mohamed, S. E. (2009). Single cell oil production by an oleaginous yeast strain in a low cost cultivation medium. Res. J. Microbiol., 4(8): 301313.

Fierro, J., Martínez, E. J., Morán, A. and Gómez, X. (2014). Valorisation of used cooking oil sludge by codigestion with swine manure, Waste Manag., 34: 1537 - 1545 .

Gohel, H. R., Ghosh, S. K. and Braganza, V. J. (2013). Yeast as a Viable and Prolonged Feedstock for Biodiesel Production. Int. J. Renew. Energy Res., 3 (1): 126 - 131.

Gouda, M. K., Omar, S. H. and Aouad, L. M. (2008). Single cell oil production by Gordonia sp. DG using agro-industrial wastes. World J. Microbl. Biotechnol., 24: 1703 - 1711.

Heba, El Bialy., Ola, M. Gomaa. and Khaled, S. A. (2011). Conversion of oil waste to valuable fatty acids using Oleaginous yeast. World J. Microbiol. Biotechnol., 27: 2791 - 2798.

Helwani, Z., Othman, M. R., Aziz, N., Fernando, W. J. N. and Kim, J. (2009).Technologies for production of biodiesel focusing on green catalytic techniques: A review. Fuel Process. Technol., 90: 1502 - 1514.

ISO 12966-2 (2011). Animal and vegetable fats and oils-Gas chromatography of fatty acid methyl esters - Part 2: Preparation of methyl esters of fatty acid, $15 \mathrm{p}$.

Johnson, V. W., Singh, M., Saini, V. S., Adhikari, D. K. and Sista, V. (1995). Utilization of molasses for the production of fat by an oleaginous yeast, Rhodotorula glutinis IIP-30. J. Indust. Microbiol., 14: 1 - 4.

Karthika, S. and Karthika, M. (2018). Production and GC-MS analysis of biodiesel from waste cooking oils using oleaginous yeast. Int. J. Pharma. Bio. Sci., 9(1): 190 - 197.

Katre, G., Joshi1, C., Khot, M., Smita, Z. and 
Ameeta, R. (2012). Evaluation of single cell oil (SCO) from a tropical marine yeast Yarrowia lipolytica NCIM 3589 as a potential feedstock for biodiesel. AMB Express. 2(36): 1 14.

Li, Q. and Wang, M. Y. (1997). Use food industry waste to produce microbial oil. Sci. Technol. Food Ind., 6, 65 - 69.

Leung, D. Y. C., Wu, X. and Leung, M. K. H. (2010). A review on biodiesel production using catalyzed transesterification. Appl. Energy, 87: 1083 - 1095.

Lin, Y. C., Hsu, K. and Chen, C. B. (2011). Experimental investigation of the performance and emissions of a heavy-duty diesel engine fueled with waste cooking oil biodiesel/ultra-low sulfur diesel blends. Energy, 36: 241 248.

Martínez, E. J., Raghavan, V., GonzálezAndrés, F. and Gómez, X. (2015). New biofuel alternatives: integrating waste management and single cell oil production. Int. J. Mol. Sci., 16: 9385 $-9405$.

Marjan, E., Azadeh, A., Iraj, N. and Mahboobeh, M. (2013). Selection and optimization of single cell oil production from Rodotorula 110 using environmental waste as substrate. J. Cell and Molec. Res., 4 (2): 68 - 75.

Noura, A. El-Naggar; Mohamed, S. E., ElFaddaly, H. A. and Wesam, I. A. S. (2011). Bioconversion of some agroindustrial by-products into single cell oil using Candida albicans NRRL Y12983 and Lipomyces starkeyi NRRL Y-11557. Res. J. Microbiol., 6(11): $784-795$.
Olkiewicz, M., Fortuny, A., Stüber, F., Fabregat, A., Font, J. and Bengoa, C. (2012). Evaluation of different sludges from WWTP as a potential source for biodiesel production. Procedia Eng., 42: 634 - 643.

Pan, L. X., Yang, D. F., Shao, L. and Li, W. (2009). Isolation of the oleaginous yeasts from the soil and studies of their lipid producing capacities. Food Technol. Biotechnol., 47: 215 - 220.

Ratanaporn, L. and Ratanaporn, B. (2011). Microbial oil production by isolated oleaginous yeast Torulaspora globosa YU5/2. Int. J. Biol. Biomolecul. Agric. Food Biotechnol. Eng., 5(4): $246-250$.

Ratledge, C. (1993). Single cell oils-Have they a biotechnological future? Trends Biotechnol., 11: 278 - 284.

White, T. J., Bruns, T., Lee, S. and Taylor, J. (1990). Amplification and direct sequencing of fungal ribosomal RNA genes for phylogenetics. In $P C R$ Protocols: A guide to Methods and Applications (ed. M. A. Innis, D. H. Gelfand, J. J. Sninsky \& T. J. White), pp. 315 -322. Academic Press: San Diego, U.S.A.

Ykema, A. E. C., Verbree, E. C., Kater, M. M. and Smit, H. (1988). "Optimization of lipid production in the oleaginous yeast Apiotrichum curvatum in whey permeate. Appl. Microbiol. Biotechnol., 29(2-3): 211 - 218.

Zhang, F., Rodriguez, S. and Keasling, J. D. (2011). Metabolic engineering of microbial pathways for advanced biofuels production. Curr. Opinion. Biotechnol., 22: 775 - 783.

\section{How to cite this article:}

Laila Ramadan, Yasser Fathy Abdelaliem and Salem Abdelfattah Mahfoz. 2019. Biodiesel Production by Pichia occidentalis MH879824.1. Int.J.Curr.Microbiol.App.Sci. 8(04): 29752987. doi: https://doi.org/10.20546/ijcmas.2019.804.344 